\title{
Factores que sostuvieron el precio de las exportaciones de harina de pescado luego de la crisis financiera mundial del 2008
}

\author{
Factors that sustained the price of fishmeal exports after the 2008 world financial crisis
}

Carlos R. Guadalupe B. ${ }^{1}$

\begin{abstract}
Resumen
Uno de los principales efectos de la globalización del comercio internacional de mercancías es su cada vez más compleja gama de interrelaciones entre diversas variables relevantes, las cuales no son fácilmente identificables. Se plantea un modelo prospectivo basado en el seguimiento estratégico del comercio internacional de las variables relevantes identificadas: exportaciones peruanas de harina de pescado, comercio internacional de harina de pescado, comercio internacional de alimentos balanceados para animales y exportaciones chinas de langostinos. El periodo de análisis (2006 - 2009) también ha sido elegido por ser uno de los más turbulentos y complicados en años recientes.
\end{abstract}

Palabras clave: harina de pescado peruana; prospectiva; análisis competitivo; comercio internacional; alimentos para animales.

\begin{abstract}
One of the main effects of the globalization of international trade in goods is its increasingly complex range of interrelations between various relevant variables, which are not easily identifiable. A prospective model is proposed based on the strategic tracking of international trade of the identified variables: Peruvian exports of fishmeal, international trade of fishmeal, international trade of balanced foods for animals and Chinese exports of prawns. The period of analysis (2006-2009) has also been chosen because it was one of the most turbulent and complicated in recent years.
\end{abstract}

Keywords: peruvian fishmeal; prospective; competitive analysis; international trade; animal food.

\section{Introducción}

La harina de pescado es el principal producto del sector pesquero (1.3 millones de TM, 2009) y el $95 \%$ del total producido se dirige a los mercados internacionales, generando US\$ 1.400 millones FOB en el 2009 (SUNAT, 2010). En el periodo 2006 - 2009 se produjeron algunos eventos que se estima deberían haber afectado negativamente la demanda internacional de harina de pescado: (1) continuó el incremento de los precios internacionales de harina de pescado; (2) los malos manejos financieros en Estados Unidos llegaron a provocar una crisis (bancarrota de bancos, financieras, empresas diversas); (3) se aplicaron cuotas individuales de pesca para anchoveta en Perú; (4) hubo menor demanda global de materias primas (commodities) y (5) se observaron indicios de comienzo de una recesión mundial, entre otros (PRODUCE, 2011).

A la fecha, la literatura revisada se limita a describir las cantidades, valores y precios de las exportaciones de harina de pescado (Sunat, 2010). No se ha identificado literatura que aplique otras técnicas, como por ejemplo, la de prospectiva (relación intuitiva con otras variables), entre otras (Dallal, 2011). Tampoco se ha trabajado con variables dinámicas, consideradas tales como aquéllas cuyos efectos varían según el tiempo y las condiciones imperantes en el entorno (Kellert, 1993).

El objetivo del presente trabajo es evaluar las interacciones entre las variables relevantes identificadas (comercio internacional de harina de pescado, alimentos balanceados y exportaciones chinas de langostinos) como aquellas que expliquen el sostenimiento de los precios internacionales de la harina de pescado, en momentos en que la economía mundial entraba en crisis (Godet, 1997).

\section{Materiales y métodos}

\section{Materiales}

\section{Fuentes de información}

Se ha aplicado el método prospectivo básico (Bas, 1999) para explicar el comportamiento de los precios internacionales de harina de pescado, basándose en las siguientes variables: (1) Exportaciones peruanas de harina de pescado; (2) Exportaciones mundiales de harina de pescado; (3) Importaciones mundiales de harina de pescado; (4) Exportaciones mundiales de alimentos balanceados; (5) Importaciones mundiales de alimentos balanceados y (6) Exportaciones chinas de langostinos y camarones. 
Se ha incluido "alimentos balanceados" debido a que es el principal uso de la harina de pescado, por tanto su demanda se deriva de la harina de pescado. Asimismo, un impulsor crítico de la demanda de alimento balanceado es la de langostinos y camarones, razón por la cual se incluye también en el presente estudio.

Como fuentes de información estadística, se ha empleado el aplicativo "Trade Map" (www.trademap.org) del Centro de Comercio Internacional (www.intracen. org). Trade Map (Trade statistics for international business development) proporciona acceso en línea a la mayor base de datos en comercio internacional, presentando indicadores de rendimiento en exportaciones e importaciones, mercados alternativos y el rol de los competidores, desde el punto de vista del producto y del país. Trade Map opera en un ambiente interactivo, basado en web, cubre los flujos comerciales (valores, cantidades, tendencias, participaciones de mercado, valores unitarios) de más de 200 países y 5300 productos, definidos en los niveles armonizados a 2, 4 y 6 dígitos. La base de datos empleada es el COMTRADE, mantenida por la División Estadística de Naciones Unidas.

Trade Map incluye: (1) análisis de mercados de exportación; (2) preselección de mercados prioritarios; (3) Revisión de competidores en mercados globales y específicos; (4) Oportunidades de diversificación de productos; (5) identificación de acuerdos comerciales y (6) Información de aranceles de importación.

Las sub partidas arancelarias armonizadas empleadas fueron: (1) Para harina de pescado se empleó la subpartida 2301.20; (2) Para alimentos balanceados, se empleó la subpartida 2309 (que incluye alimentos para perros y gatos; así como alimentos para los demás animales) y (3) La partida arancelaria para langostinos y camarones fue la 0306.13 .

\section{Metodología}

El periodo de estudio fue entre los años 2006 y 2009. Se escogió ese periodo debido a que en ese lapso las exportaciones de harina de pescado pasaron por un periodo de bonanza y luego por un periodo de crisis financiera mundial, condiciones ideales para evaluar el sostenimiento de los precios internacionales de harina de pescado. No se tomaron años recientes debido a que el objetivo de este estudio es evaluar sólo el periodo de tiempo mencionado por las razones expuestas líneas arriba.

\section{Tipo de datos}

El tipo de fuente de datos usada ha sido secundaria. Es decir, aquella publicada pero sin fines relacionados al objetivo de la investigación (Lindley, 1985). Debe precisarse que los datos empleados se han tomado desde diversos portales de Internet (Trademap, 2011), debido a que no existen documentos que cubran el periodo de estudio de interés.

\section{Resultados y discusión}

\section{Exportaciones peruanas de harina de pescado}

Las exportaciones peruanas de harina de pescado tuvieron, en el periodo 2006 - 2009, un comportamiento atípico, como se puede ver en la Fig. 1. En particular porque el 2008 ocurrió la crisis financiera mundial (la demanda internacional de materias primas cayó a partir de ese año) y en el 2009 se inició en el Perú el sistema de Cuotas Individuales de Pesca, según Decreto Legislativo $\mathrm{N}^{\circ} 1084$ (PRODUCE, 2008).

Si bien desde años anteriores - en particular desde el 2006 - se mostraba un crecimiento importante de los precios internacionales (promedio) de este insumo, en el 2008 (consecuencia de la crisis financiera internacional) se produjo una ligera caída, para luego recuperarse. Sin embargo, se debe precisar que la harina de pescado es un insumo importante para la industria mundial de alimentos balanceados para animales, por tanto las perspectivas de sus exportaciones deben considerar, además de los registros estadísticos (históricos), el comportamiento de este principal mercado.

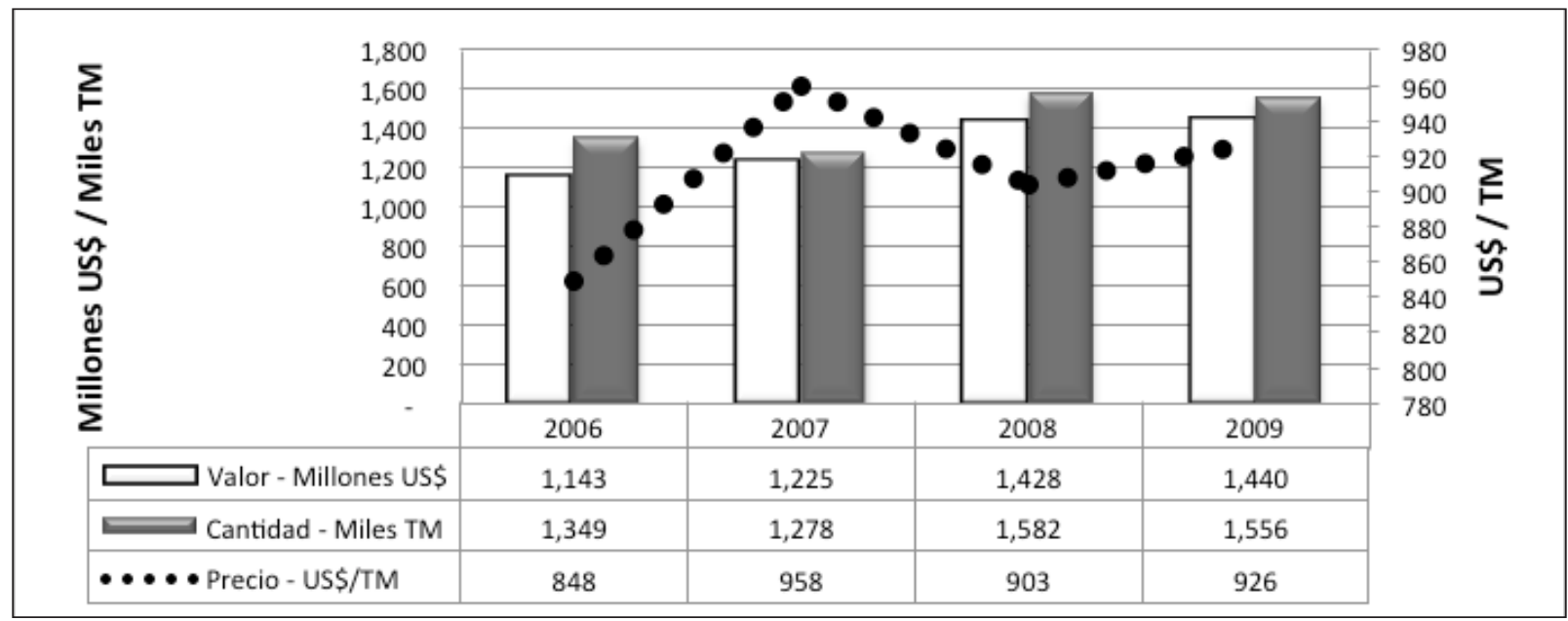

Fuente: CCI - Trademap, 2011.

Figura 1. Exportaciones peruanas de harina de pescado 


\section{Exportaciones mundiales de harina de pescado}

Perú es el principal exportador mundial de harina de pescado, representando más del $50 \%$ de la oferta mundial para el periodo en estudio. Lo sigue Chile, Alemania y otros países (más de 50). Asimismo, la tendencia de crecimiento, tanto en valor como en cantidad, ha mostrado una ligera alza en años recientes. El aumento de los precios internacionales en el 2007 fue absorbido por el mercado, aparentemente, sin mayor dificultad (ver Fig. 2). Por otra parte, tampoco se espera un significativo crecimiento de las cantidades exportadas debido a que la capacidad de captura mundial se encuentra cercana a los límites permisibles de pesca.

\section{Importaciones mundiales de alimentos balanceados}

Como se mencionó anteriormente, un componente importante para el análisis de las perspectivas del mercado harina de pescado, es el comportamiento del mercado de Alimentos Balanceados para animales. En la Fig. 3 puede apreciarse que, si bien aumentó el valor de las importaciones (30\%), las cantidades importadas disminuyeron en, aproximadamente, $11 \%$. Por el contrario, a partir del 2008, fue evidente una reducción de la demanda internacional de este producto. Esta caída de la demanda puede estimarse en cerca de $12 \%$ para el periodo 2006- 2009. Por su parte, el incremento en precios promedio alcanzó un $48 \%$.

Los principales importadores mundiales de alimento balanceado para animales fueron en el 2008: Alemania (1.942 millones US\$ CIF), Estados Unidos (1.398 millones), Reino Unido (1.328 millones), España (1.170 millones). El comportamiento de estos principales países importadores es similar: reducciones en las cantidades importadas en alrededor de $12 \%$. Sin embargo, en Reino Unido, el valor importado aumentó un $4 \%$ mientras que las cantidades demandadas cayeron en $48 \%$.

Un aspecto que llama la atención es que, hasta antes del 2008, el precio promedio de la harina de pescado era inferior al de los alimentos balanceados. Ahora esta condición se ha invertido, como puede verse en la Tabla 1 .

\section{Importaciones mundiales de harina de pescado}

Los principales países importadores de harina de pescado fueron China (34\% del total mundial), Alemania (10\%) y Noruega (17\%). Como se puede apreciar en la Fig. 4, China es el principal importador con una participación promedio (2006 - 2009) de $32 \%$ anual. Sin embargo, esta participación ha ido creciendo desde el 2006 (27\%) hasta el 2009 (34\%). Los otros países (112 países) representan entre un $48 \%$ y $60 \%$ del total mundial importado.

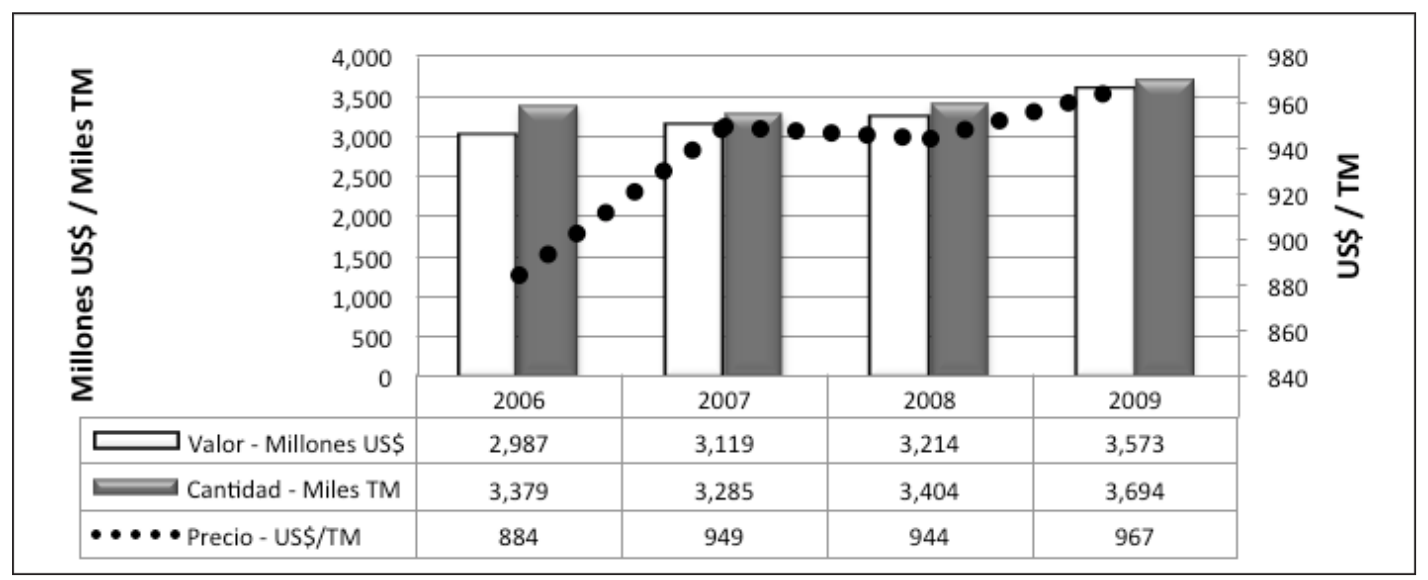

Figura 2. Exportaciones mundiales de harina de pescado

Fuente: CCI - Trademap, 2011. Consultado febrero 2012. Disponible en www.trademap.org

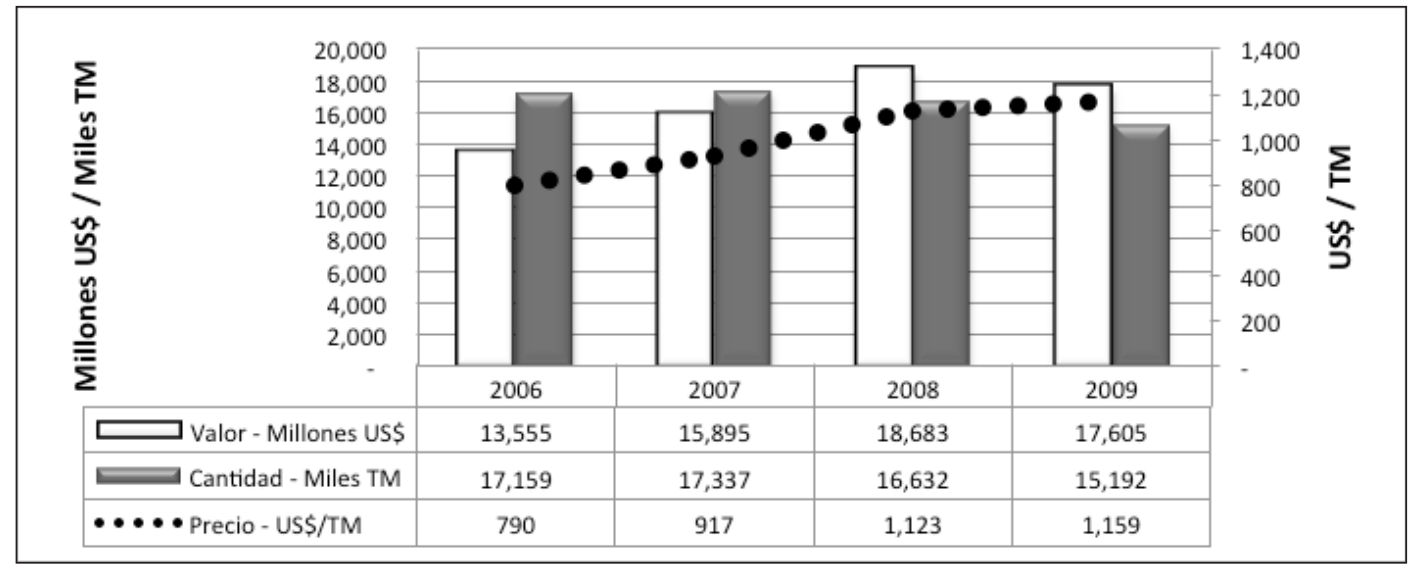

Figura 3. Importaciones mundiales de alimentos balanceados para animales 
Las importaciones en valor mantuvieron un constante crecimiento ( $11 \%$ en el periodo en estudio). Sin embargo, mientras que las cantidades cayeron en el 2007 (antes de la crisis financiera mundial) aparentemente afectadas por el notable incremento de precios del 2007 (17\%), se recuperaron significativamente en el 2008 (el año de la crisis financiera), llegando -ese año- a una tasa de crecimiento anual de $11 \%$.

Este comportamiento (altas importaciones en época de crisis financiera) fue originado por las mayores compras de China, pues fuentes especializadas indican compras especulativas (mantener inventarios ante la incertidumbre de la duración de la crisis, que fue relativamente corta).

Los demás principales países importadores (Noruega y Alemania) redujeron sus compras en el año 2008 para recuperarse en el 2009. Es decir, no realizaron compras especulativas. Por otra parte, aunque lo hicieran, su participación relativa en este mercado hubiera hecho que esto pase desapercibido.

\section{Precios internacionales de harina de pescado}

La evolución de los precios internacionales se aprecia en la Fig. 5. El caso de Noruega merece especial mención, pues paga alrededor de $20 \%$ más que los demás países importadores. No existe discriminación de precios por orígenes, pues adquiere harina tanto de Perú y Chile como de Dinamarca e Islandia. Sin embargo, en general, excluyendo el caso de China (no es importador de alimentos balanceados), si se compara las importaciones mundiales de alimentos balanceados con las de harina de pescado, el mercado parece estar absorbiendo los incrementos de precio de la materia prima. Incluso, las cantidades importadas están creciendo.

\section{Exportaciones chinas de langostinos}

Un producto que requiere importantes cantidades de harina de pescado para sus alimentos balanceados es el langostino (incluyendo camarones y similares), de allí su inclusión en este análisis. La estrategia de crecimiento de las exportaciones acuícolas chinas incluye su diversificación comercial (más países de destino). Como se puede apreciar en la Fig. 6, el crecimiento registrado en el año 2009, en valor, ha sido significativo.

Se entiende ahora la necesidad de harina de pescado para elaborar alimentos balanceados dirigidos a la acuicultura, lo que originó el crecimiento de los precios internacionales de harina de pescado. Los principales mercados de destino de las exportaciones de langostinos y camarones de China pueden verse en la Fig. 7.

A su vez, los precios internacionales de langostinos y camarones logrados por China han sido alentadores, como se ve en la Fig. 8. En casi todos sus principales mercados de exportación el crecimiento ha sido sustancial, excepto en Estados Unidos y España.

Tabla 1. Relación precio alimento balanceado/harina de pescado

\begin{tabular}{cccc}
\hline Año & $\begin{array}{c}\text { Precio Harina de Pescado } \\
\text { (US\$ / TM) }\end{array}$ & $\begin{array}{c}\text { Precio Alimento Balanceado } \\
\text { (US\$/TM) }\end{array}$ & $\begin{array}{c}\text { Relación } \\
\text { Alimento B. / Harina Pescado }\end{array}$ \\
\hline 206 & 884 & 790 & 0.89 \\
207 & 949 & 917 & 0.97 \\
208 & 944 & 1,123 & 1.19 \\
209 & 967 & 1,159 & 1.20 \\
\hline
\end{tabular}

Fuente: CCI - Trademap, 2011. Consultado febrero 2011. Disponible en www.trademap.org

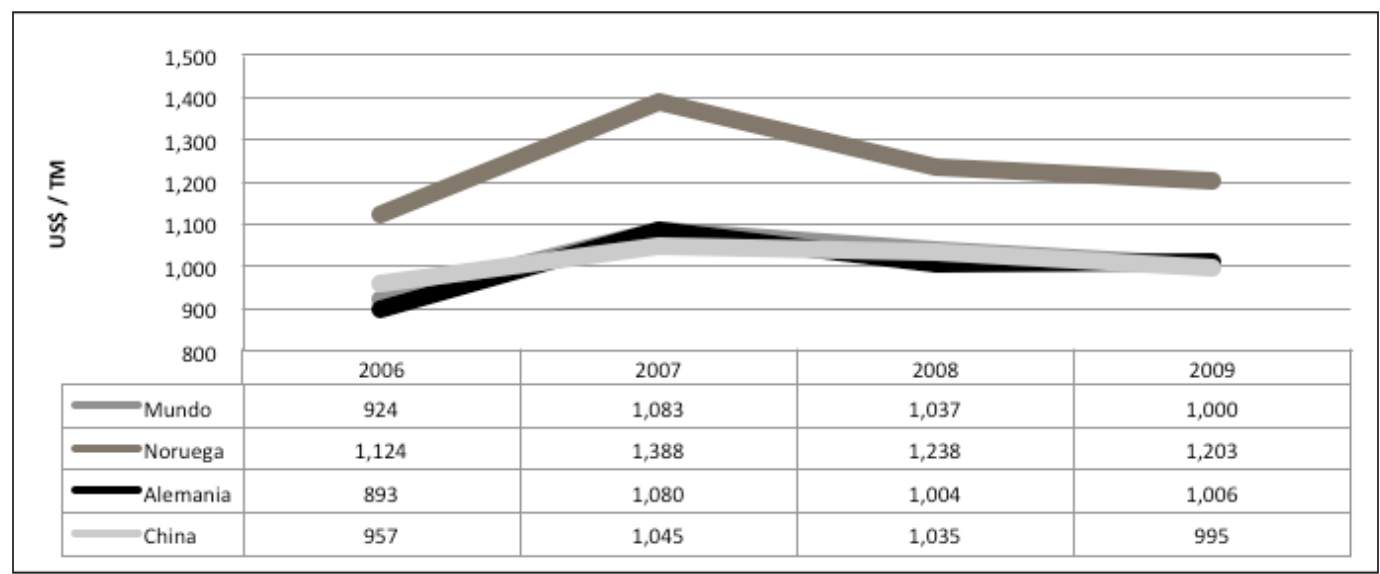

Figura 4. Importaciones mundiales de harina de pescado, por países, en valor Fuente: CCI - Trademap, 2011. Consultado febrero 2011. Disponible en www.trademap.org 


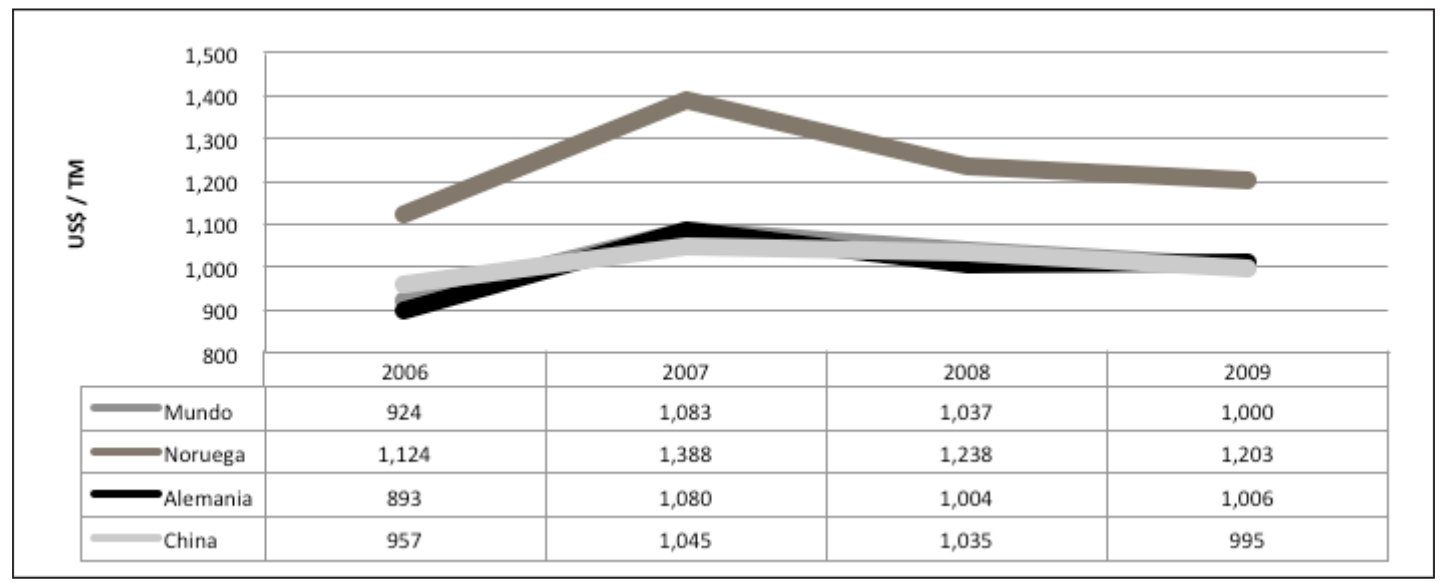

Figura 5. Importaciones mundiales de harina de pescado, por países, precios internacionales Fuente: CCI - Trademap, 2011. Consultado febrero 2011. Disponible en www.trademap.org

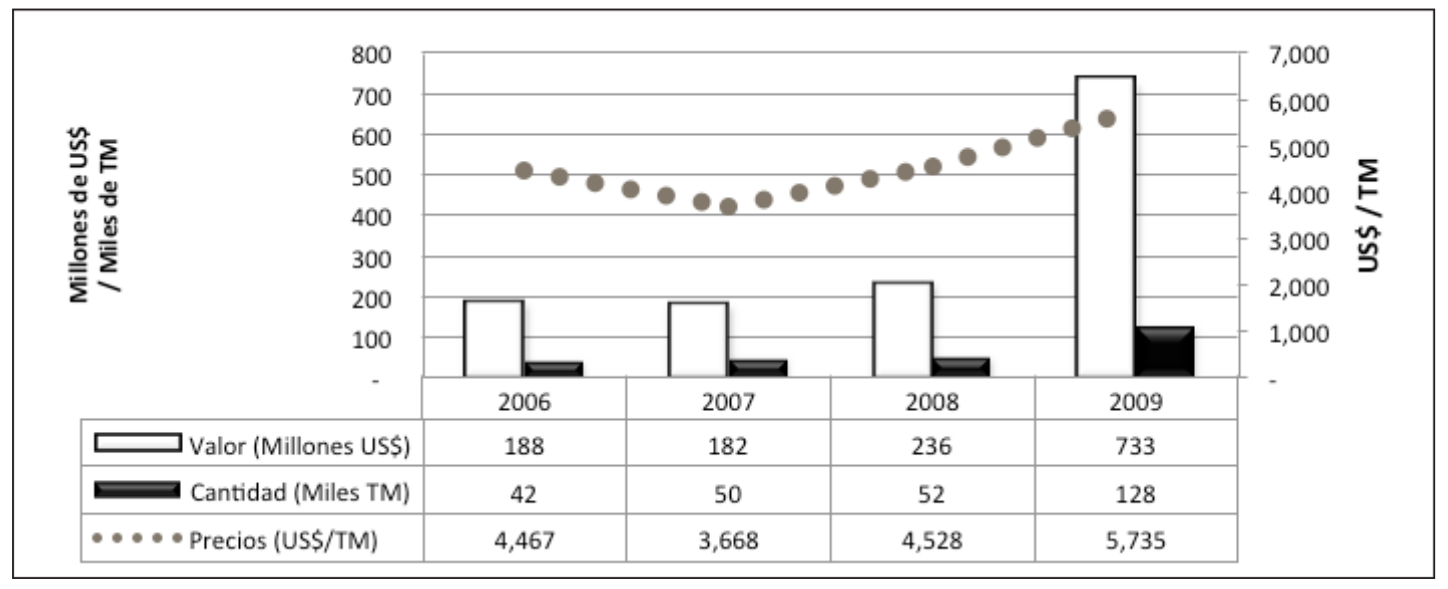

Figura 6. Exportaciones chinas de langostinos y camarones Fuente: CCI - Trademap, 2011. Consultado febrero 2011. Disponible en www.trademap.org

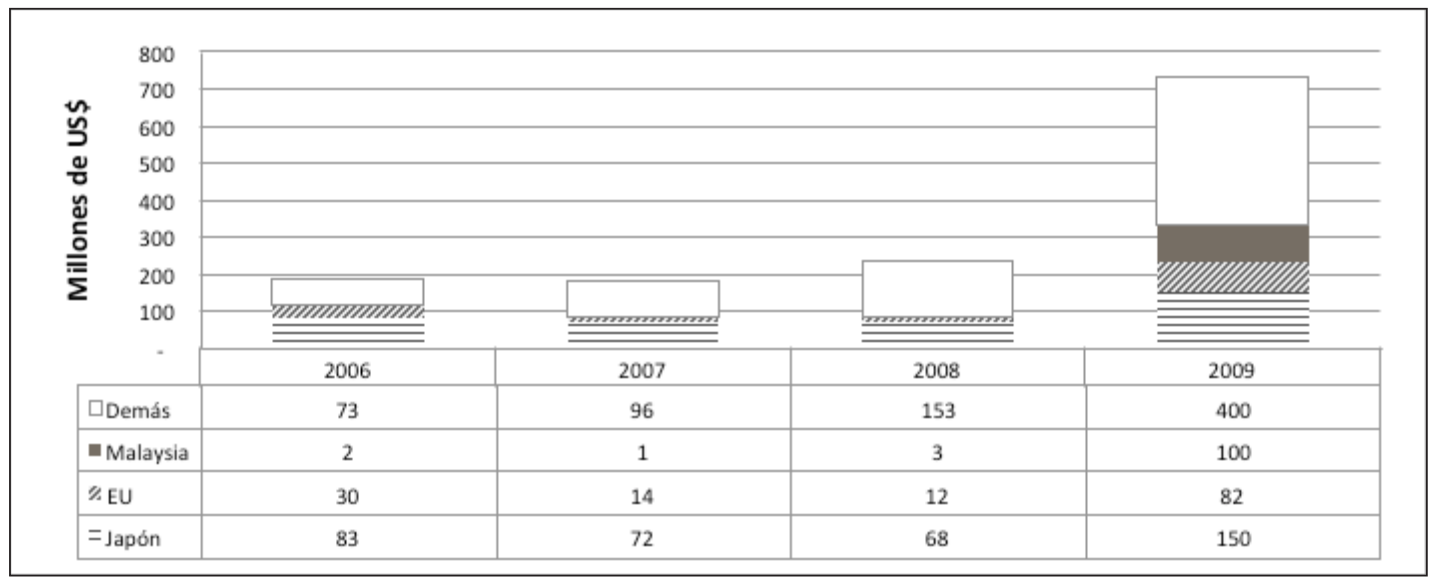

Figura 7. Exportaciones chinas de langostinos y camarones, por países Fuente: CCI - Trademap, 2011. Consultado febrero 2011. Disponible en www.trademap.org

\section{Conclusiones}

Las cantidades ofertadas de harina de pescado se han mantenido a pesar de los inusualmente altos niveles de los precios internacionales (se ha duplicado en años recientes). La demanda internacional para la harina de pescado tiene dos grandes tipos de compradores, diferenciados por sus estrategias de compra. Por un lado China (compra el $33 \%$ de la oferta mundial de harina) cuyo aumento de demanda origina el incremento de precios. Por otra parte están los demás países (en general, pequeños compradores), que han resentido el incremento de precios, disminuyendo las cantidades demandadas, pero recuperándose posteriormente. Como son "pequeños clientes" siguen las tendencias generadas por el "gran cliente": China. La demanda de alimentos balanceados para animales ha mostrado una leve caída, la 


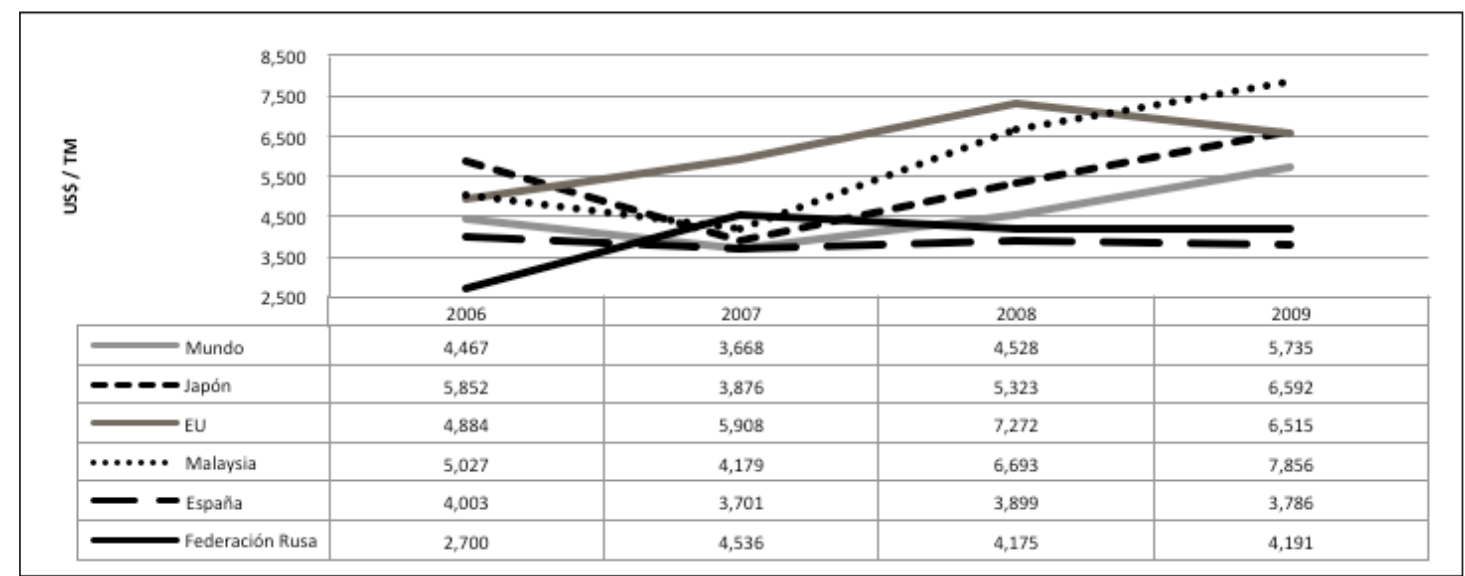

Figura 8. China: precios de exportación de langostinos y camarones, por países Fuente: CCI - Trademap, 2011. Consultado febrero 2011. Disponible en www.trademap.org

cual puede deberse a los mayores precios de su principal insumo (la harina de pescado). El comportamiento de los precios internacionales ha sido muy cambiante y estas variaciones han alterado significativamente las estrategias comerciales de los principales clientes. Si bien China es el principal cliente, no es buena práctica comercial concentrar las ventas en un solo mercado que, de acuerdo a lo observado puede aumentar o reducir sus compras (acumulando o liberando inventarios en los mercados internacionales) de manera difícilmente predecible (a menos que se cuente con un observador cercano a las políticas de compra - importaciones de China). China se mantendrá fuerte en su demanda de harina de pescado mientras que la de alimento balanceado para su acuicultura permanezca fuerte. Esta, a su vez, dependerá de la demanda internacional de sus principales productos de exportación acuícola, en particular, de langostinos y camarones.

\section{Literatura citada}

BAS, Prospectiva; herramientas para la gestión estratégica del cambio.

Barcelona, A. 1999. Papers 59, 1999 223-229158 pàgines. Disponible en: file://C:/Users/of\%20Investig/ Downloads/1268-4916-1-SM.pdf

Dallal, G. E. (s.f.). The Little Handbook of Statistical Practice. Tufts University.

Godet, M. 2004. Creating Futures Scenario Planning as a Strategic Management Tool. Economica.

Kellert, S. 1993. In the Wake of Chaos: Unpredictable Order in Dynamical Systems. University of Chicago Press, p. 32, ISBN 0-226-42976-8.

PRODUCE. Ministerio de la Producción. (s.f.). Recuperado de www.PRODUCE.gob.pe.

Superintendencia de Administración Tributaria [SUNAT]. (s.f.). Disponible en: www.sunat.gob.pe 